\section{The Primary Health Care Approach and Restructuring of the MB ChB: A Case Study at the Faculty of Health Sciences, University of Cape Town}

By Nadia Hartman. Lambert Academic Publishing, 2014. ISBN: 978-3-8484-4941-5. info@lap-publishing.com

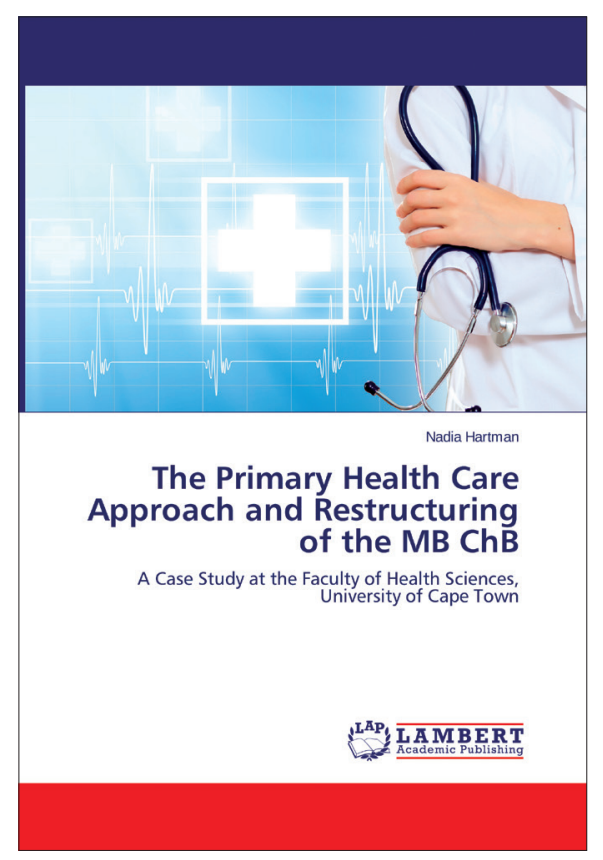

This is a significant book in many ways, and essential reading for anyone involved in health sciences education. It is important for three reasons: firstly, it is a South African product, and more scholarship grounded in the African context is sorely needed. Secondly, it is originally conceptualised and rigorously constructed, based on the challenging experience of curriculum restructuring over a number of years, 'wrested from the vicissitudes of curriculum reform, as a colleague put it. And, thirdly, but most importantly, it succeeds in doing what many might imagine as impossible, namely to measure the primary healthcare approach (PHCA) in education.

PHC is often misunderstood, and either equated with primary care/first-contact care, or lost in a confusing array of jargon that begins with vaguely remembered phrases from the Alma-Ata Declaration of 1978. However, that was more than 35 years ago, and although it still remains relevant in terms of the imperative of Health for All, a significant shift occurred in 2008. The World Health Report of that year by the World Health Organization, 'Primary Health Care: Now More than Ever', included a central chapter entitled 'Putting people first', indicating a move away from a purely public health orientation towards a more balanced relationship between clinical practice and public health. The ideas of community-orientated primary care have come to the fore once again, more than 50 years after these were first proposed, and the biomedical approach that is applicable to individual patient care is balanced with the need for a wider view of health at a community level.

Thus, the author constructs out of the literature and a series of carefully documented key informant interviews, a hierarchy of understanding of the PHCA for educational purposes: from the biopsychosocial approach, through comprehensive care, through the $\mathrm{PHC}$ principles to the $\mathrm{PHC}$ philosophy. Using her sociological background, she then rates each on a scale from very limited embodiment to full embodiment, indicating the degree of implementation of the PHC philosophy in practice. This framework is used to construct a PHCA Index, which is then systematically applied to the University of Cape Town's MB ChB programme, examining the Faculty of Health Sciences' strategic plan, the curriculum blueprint, and the programme itself. The author chooses a case study approach of one university to describe the issues to the necessary level of complexity, which works well. Not surprisingly, the results show a lack of curriculum alignment when placed under the spotlight of the PHCA Index, and a tendency to default to the biomedical approach in actual implementation, particularly later in the curriculum, despite the explicit intention to follow the PHC approach. For an explanation of the discrepancy between intention and practice, she turns to Pierre Bourdieu's theory of habitus, agency and power, which is brilliantly applied to the study.

This rigorous analysis not only allows a depth of understanding of educational development that has not been documented before, but gives deep insight into the underlying dynamics of the inherent tensions and assumptions that are frequently made in revising and reconstructing curricula.

Most importantly, however, it demonstrates from an educational perspective, in its conceptualisation and execution, what it means to take PHC seriously. It deserves to be read and digested by all health science educators who are prepared to look below the surface of their teaching practices and examine their underlying assumptions.

\section{Steve Reid}

Primary Health Care Directorate

Faculty of Health Sciences

University of Cape Town

South Africa

steve.reid@uct.ac.za 